\title{
A double-hit in vivo model of GBA viral microRNA- mediated downregulation and human alpha- synuclein overexpression demonstrates nigrostriatal degeneration
}

\author{
Alexia Polissidis ( $\sim$ apolissidis@bioacademy.gr) \\ Biomedical Research Foundation of the Academy of Athens: Idryma latrobiologikon Ereunon tes \\ Akademias Athenon https://orcid.org/0000-0002-7284-7003
}

\section{Georgia Nikolopoulou}

Biomedical Research Foundation of the Academy of Athens: Idryma latrobiologikon Ereunon tes Akademias Athenon

Effrosyni Koronaiou

Biomedical Research Foundation of the Academy of Athens: Idryma latrobiologikon Ereunon tes Akademias Athenon

\section{Maria Nikatou}

Biomedical Research Foundation of the Academy of Athens: Idryma latrobiologikon Ereunon tes Akademias Athenon

\section{Catherine Viel}

Sanofi Genzyme

\section{Marios Bogiongko}

Biomedical Research Foundation of the Academy of Athens: Idryma latrobiologikon Ereunon tes Akademias Athenon

\section{S. Pablo Sardi}

Sanofi Genzyme

\section{Maria Xilouri}

Biomedical Research Foundation of the Academy of Athens: Idryma latrobiologikon Ereunon tes Akademias Athenon

\section{Kostas Vekrellis}

Biomedical Research Foundation of the Academy of Athens: Idryma latrobiologikon Ereunon tes Akademias Athenon

\section{Leonidas Stefanis}

Biomedical Research Foundation of the Academy of Athens: Idryma latrobiologikon Ereunon tes Akademias Athenon 


\section{Research article}

Keywords: GBA, glucocerebrosidase, alpha-synuclein, neurodegeneration, animal model, mouse, neuroinflammation, nigrostriatal system, in vivo

Posted Date: July 24th, 2021

DOI: https://doi.org/10.21203/rs.3.rs-721944/v1

License: (c) (i) This work is licensed under a Creative Commons Attribution 4.0 International License.

Read Full License

Version of Record: A version of this preprint was published at Neurobiology of Disease on January 1st, 2022. See the published version at https://doi.org/10.1016/j.nbd.2022.105612. 


\section{A double-hit in vivo model of GBA viral microRNA-mediated downregulation}

and human alpha-synuclein overexpression demonstrates nigrostriatal

\section{degeneration}

Alexia Polissidis ${ }^{a} \quad$ apolissidis@bioacademy.gr, Georgia Nikolopoulou ${ }^{\text {b,1 }}$ geonikolopoulou@yahoo.gr, Effrosyni Koronaiou ${ }^{a}$ ekoronaiou@bioacademy.gr, Maria Nikatou $^{\mathrm{a}}$ nikatou90@gmail.com, Catherine Viel ${ }^{\mathrm{c}}$ Catherine.Viel@sanofi.com, Marios Bogiongkoa snmarios91@gmail.com, S. Pablo Sardi ${ }^{\mathrm{C}}$ Pablo.Sardi@sanofi.com, Maria Xilouri ${ }^{\mathrm{a}}$ mxikouri@bioacademy.gr, Kostas Vekrellisbvekrellis@bioacademy.gr, Leonidas Stefanis ${ }^{\mathrm{a}, \mathrm{d}}$ Istefanis@bioacademy.gr

${ }^{a}$ Center of Clinical, Experimental Surgery and Translational Research, Biomedical Research Foundation of the Academy of Athens (BRFAA), 4 Soranou Efesiou St, 11527, Athens, Greece. ${ }^{b}$ Center of Basic Research, BRFAA, 4 Soranou Efesiou St, 11527, Athens, Greece.

${ }^{\mathrm{c}}$ Rare and Neurologic Diseases Research Therapeutic Area, Sanofi, Framingham, MA 01701, USA.

${ }^{d} 1^{\text {st }}$ Department of Neurology, Eginition Hospital, Medical School, National and Kapodistrian University of Athens, 11527, Athens, Greece.

${ }^{1}$ Present address: $\quad 2^{\text {nd }}$ Neurological Department, Henry Dunant Hospital Center, 107 Mesogeion Ave, 11526, Athens, Greece

*To whom correspondence should be addressed:

Alexia Polissidis, email: apolissidis@bioacademy.gr

Leonidas Stefanis, email: 1stefanis@,bioacademy.gr 
Center of Clinical, Experimental Surgery and Translational Research,

Biomedical Research Foundation of the Academy of Athens (BRFAA), Soranou Efesiou 4, Athens, 11527, Greece.

\section{Abstract}

Background: Preclinical and clinical studies support a strong association between mutations in the GBA1 gene that encodes beta-glucocerebrosidase (GCase) (EC 3.2.1.45; glucosylceramidase beta) and Parkinson's disease (PD). Alpha-synuclein (AS), a key player in PD pathogenesis, and GBA1 mutations may independently and synergistically cause lysosomal dysfunction and thus, embody clinically well-validated targets of the neurodegenerative disease process in PD. However, double-hit in vivo models, recapitulating pathological features of PD that can be used to dissect the nature of the complex relationship between GCase and AS on the nigrostriatal axis, the region particularly vulnerable in PD, are direly needed.

Methods: To address this, we implemented a bidirectional approach in mice to examine the effects of: 1) GCase overexpression (wild-type and mutant N370S) on endogenous AS levels and 2) downregulation of endogenous GCase combined with AS overexpression.

Results: Striatal delivery of viral-mediated GCase overexpression revealed minimal effects on cortical and nigrostriatal AS tissue levels and no significant effect on dopaminergic system integrity. On the other hand, microRNA (miR)-mediated GBA1 downregulation (miR GBA), combined with virus-mediated human AS overexpression (+AS), yields decreased GCase activity in the cortex, mimicking levels seen in GBA1 heterozygous carriers $(30-40 \%)$, increased astrogliosis and microgliosis, decreased striatal dopamine levels (50\% compared to controls) and loss of nigral dopaminergic neurons ( $\sim 33 \%)$ - effects that were all reversible with 
miR rescue. Most importantly, the synergistic neurodegeneration of miR GBA+AS correlated with augmented AS accumulation and extracellular release in the striatum.

Conclusion: Collectively, our results suggest that GCase downregulation alone is not sufficient to recapitulate key pathological features of PD in vivo, but its synergistic interplay with AS, via increased AS levels and release, drives nigrostriatal neurodegeneration. Furthermore, we demonstrate a novel double-hit model that can be used to identify putative mechanisms driving PD pathophysiology and can be subsequently used to test novel therapeutic approaches.

\section{Keywords}

GBA, glucocerebrosidase, alpha-synuclein, neurodegeneration, animal model, mouse, neuroinflammation, nigrostriatal system, in vivo

\section{Background}

GBA1 gene mutation (hereon referred to as GBA) heterozygosity is one of the most common genetic risk factors for Parkinson's disease (PD) with a predicted frequency of $7 \%$ to $10 \%$ in the PD population (1-3). The GBA gene encodes for glucocerebrosidase (GCase), a lysosomal enzyme responsible for the breakdown of glucosylceramide (GlcCer) to glucose and ceramide. GBA-associated PD (GBA-PD) exhibits a comparable symptomatic presentation to sporadic PD but with more rapid cognitive and motor decline and a slightly earlier average age of onset (4-6). Several clinical studies provide compelling evidence for a reciprocal detrimental relationship between GCase (loss of function) and aberrant alpha-synuclein (AS) (toxic gain of function). For example, heterozygous mutant GBA1 carriers demonstrate increased post-mortem levels of AS, while sporadic cases of PD have decreased brain GCase 
activity associated with early accumulation of AS, inflammation, dysregulation of chaperonemediated autophagy and lipid metabolism (7-9).

The central role of AS accumulation in GBA-PD is emphasized by the reciprocal relationship between GCase activity and AS demonstrated in SH-SY5Y cell cultures, neuronal cultures, conduritol-B-epoxide (CBE)-treated mice and transgenic GBA mouse models (1016,16-18). In addition, several preclinical studies have demonstrated the successful amelioration of neurodegenerative phenotypes in murine synucleinopathy models by either enhancing GCase activity in the central nervous system (15) or by targeting the GCase pathway indirectly via inhibition of glucosylceramide synthase (19). Conversely, cell and mouse models have demonstrated that increased AS causes a decrease in GCase activity $(13,20)$.

Considering the prevalence of GBA1 mutations and the role both GCase and AS play in PD, understanding how GBA affects the susceptibility to AS-mediated nigral toxicity in vivo is crucial for understanding PD pathogenesis and successfully slowing or blocking the underlying neurodegenerative process with future disease-modifying treatments. However, the overall utility of currently available murine models is limited (reviewed extensively in (21). Here, we sought to recapitulate key pathological PD features, i.e. nigral neurodegeneration, neuroinflammation, and AS accumulation, to generate a model of GBA heterozygosity that more closely represents the haploinsufficiency as seen in GBA carriers and assess its association with AS accumulation and PD pathogenesis.

\section{Materials and Methods}

In vitro experiments 
For the in vitro experiments, HEK293T cells were double transfected with AAV plasmids carrying the human GBA (wild-type (WT) or mutant N370S, D409V, L444P) or green fluorescent protein (GFP) (as control group) together with human AS using the calcium phosphate method in separate concentrations of $0.75 \mu \mathrm{g}$ (1:1 ratio). After transfection, the plate was incubated at $39^{\circ} \mathrm{C}$ for 24 hours in 1-\% FBS DMEM (plasmids contain a Gus B thermosensitive promoter). The plate was then incubated at $37^{\circ} \mathrm{C}$ for 48 hours in $2 \%$ FBS DMEM and the medium was switched from full to $2 \%$ FBS. The medium was collected and spun down twice at 2000 and 4000 rpm and the cells were lysed in Triton-X soluble buffer and further analyzed by Western Blot analysis and ELISA.

For the in vitro experiments with microRNA GBA plasmid, Neuro2A cells were transfected with lipofectamine 2000 (Invitrogen) following the manufacturer's instruction vs. GFP as control (Table 1). The cells were incubated as above for HEK293T cells. The cells were collected $72 \mathrm{~h}$ post-transfection and lysed in Triton-X soluble buffer and analyzed by Western Blot.

\section{Animals}

Eight-week-old male wild-type C57BI/6 mice (27-33 g body weight) were housed with free access to food and water under a 12-h light/dark cycle. All experimental procedures performed were approved by the Ethical Committee for Use of Laboratory Animals of the Biomedical Research Foundation Academy of Athens and in accordance with the ARRIVE guidelines the EU Directive 2010/63/EU for animal experiments.

\section{AAV vectors}


For experiment 1, recombinant human serotype 5 adenoviruses ( $\mathrm{rAd}$ ) expressing fulllength human wild-type (WT), D409V, L444P and N370S GBA were generated, as previously described (Papadopoulos et al. 2018, He et al. 1998). For experiment 2, adeno-associated viral vectors (AAVs) were used to downregulate GCase expression with an artificial microRNA (miR)-based hairpin targeting mouse GBA1 (miR GBA), control vector with a scrambled miR (miR control) or co-transduced with GFP where indicated (miR control-GFP), rescue vector expressing a miR-resistant GBA (i.e. a series of synonymous mutations were introduced to the human GBA coding sequence to generate AAV2/1-GusB-GBA*- miR-Gba, where GBA* is resistant to the artificial $\mathrm{miR}$ ) and vector overexpressing human AS have been previously described (Sardi et al., 2011, Jackson et al. 2019). For experiment 1, subjects were assigned to one of three treatment groups: GFP, WT and N370S; and for experiment 2, subjects were assigned to one of six treatment groups: miR control +/- AS, miR GBA +/- AS and miR rescue GBA +/- AS (see table 1 for the list of viruses and titers).

\begin{tabular}{|c|c|c|}
\hline $\begin{array}{c}\text { Treatment } \\
\text { (abbreviated) }\end{array}$ & Virus name & $\begin{array}{l}\text { Virus Titer (viral } \\
\text { particles }(v p) / \mu l)\end{array}$ \\
\hline \multicolumn{3}{|c|}{ Experiment 1: GBA overexpression } \\
\hline GFP & rAd-GFP & $1.51 \times 10^{8}$ \\
\hline WT GBA & rAd-WT GBA & $2.31 \times 10^{8}$ \\
\hline N370S & rAd-N370S & $5.9 \times 10^{8}$ \\
\hline \multicolumn{3}{|c|}{ Experiment 2: GBA downregulation \& AS overexpression } \\
\hline miR control & AAV2/1 CBA-miR-Control & $2.80 \times 10^{12}$ \\
\hline miR control-GFP & AAV1 sc-GFP & $5.8 \times 10^{12}$ \\
\hline miR GBA & AAV2/1 EGFP-miRNA-gba1 B & $3.30 \times 10^{13}$ \\
\hline miR rescue & AAV2/1 scGusB-GC*-miR gbaB & $3.40 \times 10^{12}$ \\
\hline AS & AAV1-CBA-aSynuclein & $6.30 \times 10^{12}$ \\
\hline
\end{tabular}

Table 1: Names and titers of AAVs injected in C57BI/6 mice striata; miR= microRNA, AS= $\alpha$-synuclein.

\begin{tabular}{|c|l|}
\hline Treatment & Abbreviation \\
\hline microRNA control (GFP) - human AS & miR CTL - AS \\
\hline
\end{tabular}




\begin{tabular}{|l|l|}
\hline microRNA GBA (GFP) - human AS & miR GBA - AS \\
\hline microRNA rescue - human AS & miR Resc - AS \\
\hline microRNA control (GFP) + human AS & miR CTL + AS \\
\hline microRNA GBA (GFP) + human AS & miR GBA + AS \\
\hline microRNA rescue + human AS & miR Resc + AS \\
\hline
\end{tabular}

Table 2: Experiment 2 in vivo GBA downregulation: The 6 virus-injected experimental groups and their abbreviations; $\mathrm{AS}=\alpha$-synuclein .

\section{Surgical Procedures}

All surgical procedures were performed under isoflurane (Abbott, B506) anesthesia. Animals were given i.p. carpofen (dose) for analgesia. After placing the animal into a stereotaxic frame (Kopf Instruments, USA), $2 \mu \mathrm{l}$ of AAV solution (with final titer of 3.3 E13 $\mathrm{gc} / \mathrm{mL}$ ) and $1 \mu \mathrm{l}$ of DPBS or human AS was injected unilaterally into the right striatum using the following coordinates: $-0.5 \mathrm{~mm}$ anteroposterior, $+1.6 \mathrm{~mm}$ mediolateral from the bregma, and $-3.4 \mathrm{~mm}$ dorsoventral from the skull, according to the mouse stereotaxic atlas (22). Injections were performed using a finely pulled glass capillary (diameter of approximately 60$80 \mu \mathrm{m})$ attached to a Hamilton syringe with a 22 gauge needle. After delivery of the viral vector using an injection rate of $0.1 \mu \mathrm{L} / 15 \mathrm{sec}$, the capillary was held in place for 5 min, retracted $0.1 \mu \mathrm{m}$, and, after $2 \mathrm{~min}$, was slowly withdrawn from the brain, as previously described (23).

\section{Immunohistochemistry}


Four and eight weeks post-injection (WPI), animals were perfused under isoflurane anesthesia. The perfusion was performed through the ascending aorta using approximately $30 \mathrm{~mL}$ of $1 X$ PBS for blood clearance and then $50 \mathrm{~mL}$ of $4 \%$ paraformaldehyde (PFA) for tissue fixation. The brains were removed and post-fixated overnight in 4\% PFA, then transferred to $15 \%$ sucrose overnight followed by $30 \%$ sucrose overnight. The brains were then frozen using isopentane on ice $\left(-55^{\circ} \mathrm{C}\right)$ and stored at $-80^{\circ} \mathrm{C}$ until analysis. The perfused brains were cryosectioned through the coronal plane in $30 \mu \mathrm{m}$ increments.

For immunohistochemical analysis, striatal and nigral sections were washed with PBS, followed by antigen retrieval with $10 \mathrm{mM}$ citrate buffer at $80^{\circ} \mathrm{C}$ for 20 minutes, then placed on ice for an additional 20 minutes. The sections were then blocked using $5 \%$ normal goat serum (NGS) and $0.1 \%$ Triton-X for 1 hour at room temperature. Subsequently, the sections were incubated for 48 hours at $4^{\circ} \mathrm{C}$ with the following primary antibodies: anti-GBA (1:500; human 8E4; human and rodent G4171, Sigma-Aldrich), anti-human $\alpha$-synuclein (syn211) (1:150,000; , 36-008, Millipore), anti-GFP (1:2000; 13970, Abcam), anti-TH (1:2000; AB152 MAB318, Millipore), anti-dopamine transporter (DAT; 1:2000; AB2231, Sigma-Aldrich), antiGFAP (1:750, Z0334, DAKO) anti-AIF-1/lba1 (1:1000, 019741 DAKO); and secondary antibodies: CF488A (1:2000; 20010, 20012 Biotium), CF555 (1:2000, 20030, 20033 Biotium), Affinipure Cy5 (1:400, 115- 175-146 Jackson Immunoresearch), and DAPI (1:2000; Sigma).

\section{Total RNA isolation and reverse transcription}

Midbrain tissue was dissected from mouse brains and total RNA was isolated. For this purpose, $1 \mathrm{~mL}$ of TRIZOL was used per $50-100 \mathrm{mg}$ of tissue, followed by centrifugation at $12,000 \times$ for 10 minutes at $4^{\circ} \mathrm{C}$. The supernatant was transferred to a new tube and incubated for 5 minutes at room temperature. Afterwards, $0.2 \mathrm{~mL}$ of chloroform was added per $1 \mathrm{~mL}$ of 
TRIZOL reagent. The tubes were shaken vigorously for 15 seconds and incubated again at room temperature for 3 minutes, followed by centrifugation at $12000 \times$ for 15 minutes at $4^{\circ} \mathrm{C}$. The mixture was separated into a lower red, phenol-chloroform phase, an interphase, and a colorless upper aqueous phase, which contains the RNA. The aqueous phase was transferred to a new tube and the RNA was precipitated using $0.5 \mathrm{~mL}$ of isopropyl alcohol per $1 \mathrm{~mL}$ of TRIZOL. Samples were incubated overnight at $-20^{\circ} \mathrm{C}$ and were centrifuged again at $12000 x g$ for 10 minutes at $4^{\circ} \mathrm{C}$ and the supernatant was then completely removed, leaving only the RNA pellet which was washed using $75 \%$ ethanol (1:1 TRIZOL). After another centrifugation at $7500 \mathrm{xg}$ for 5 minutes at $4^{\circ} \mathrm{C}$, the pellets were air dried and dissolved in RNase-free $\mathrm{H}_{2} \mathrm{O}$. Concentration was measured using spectrometry and RNA integrity was assessed by running $500 \mathrm{ng}$ of each sample on a 1\% agarose gel.

DNase treatment was then performed (RQ1 10x buffer, RQ1 DNase by Promega, 30 minutes at $37^{\circ} \mathrm{C}$ ) and stopped by adding $1 \mu \mathrm{L}$ of DNase Stop Solution (Promega) to the sample and incubating for 10 minutes at $65^{\circ} \mathrm{C}$. Finally, $1 \mu \mathrm{L}$ of oligo dT per sample was added and the samples were incubated for 5 minutes at $70^{\circ} \mathrm{C}$. For the cDNA synthesis, we used $5 \mu \mathrm{L}$ of $5 \mathrm{X} R \mathrm{RT}$ buffer (Promega), $5 \mu \mathrm{L}$ of dNTPs, $1 \mu \mathrm{L}$ of RNaseOUT (Promega) and $1 \mu \mathrm{L}$ of reverse transcriptase (M-MLV RT, Promega) and incubated the samples for 1 hour at $37^{\circ} \mathrm{C}$. qPCR was then performed.

\section{Confocal microscopy and analysis}

Images from the stained sections were obtained using confocal microscopy (Leica SP5 mark II with conventional photon-multiplier tube, at $23^{\circ} \mathrm{C}$ using the Leica Advanced Fluorescence v2.7 acquisition software (Leica Microsystems, Wetzlar, Germany)). After acquiring representative images, quantification of the stained proteins was done using Imaris 
(Version 8.0) for GBA or ImageJ for AS. For each animal, two sections per brain area were used and a total of 3 images per section were obtained.

For GBA quantification ( $n=5$ for $4 \mathrm{WPI}, \mathrm{n}=3$ for $8 \mathrm{WPI}$ ), the surface function of the Imaris software was used to select only GFP-positive cells by appropriately adjusting the number of voxels as well as the intensity of the GFP channel in the threshold tab. The intensity of GBA was then calculated by masking the GBA channel within the selected surfaces.

For the quantification of human AS ( $n=4-6)$ in the striatum and substantia nigra, the entire surface using DAPI intensity or TH positive somata, respectively, was selected and the threshold was adjusted appropriately, after converting the image to 8-bit. The selected area was assigned as the region of interest (ROI) and using the measure tool, intensity of human AS staining within the ROI was determined.

\section{Glucocerebrosidase activity measurements}

Brain glucocerebrosidase activities were determined as previously described using 4methylumbelliferyl- $\beta$ - $d$-glucopyranoside (4-MU) as the artificial substrate in striatal tissue (15) and cortical tissue (24).

\section{Glycosphingolipid level measurements}

Striatal tissue levels of glucosylceramide (GlcCer), glucosylsphingosine (GlcSph), and ceramide (Cer) were measured by liquid chromatography and tandem mass spectrometry (LCMS/MS) as previously described (15). 
Spontaneous locomotor activity was assessed at 4 and 8 WPI. Briefly, animals were placed in a Plexiglas cylinder (dimensions) and allowed to move freely for $5 \mathrm{~min}$. Videos were recorded from below with a mobile phone camera (selfie mode) and total number of rearings (left, right, and both forelimb placements) and distance travelled $(\mathrm{cm})$ were analyzed manually and with Ethovision XT9.0 software (Noldus).

\section{Results}

Experiment 1: GCase overexpression and measurement of endogenous AS levels

\section{Mutant N370S GCase decreases secreted AS in vitro}

Wild-type GBA (WT GBA) GCase overexpressing HEK293 cells demonstrated enhanced GCase enzymatic activity levels compared to the control group $(p<0.0001)$ while the overexpression of the PD-linked mutant GCase forms (N370S, D409V, L444P) did not alter GCase enzyme activity (SF1A). Furthermore, intracellular AS levels remained largely unaffected by WT or mutant GCase overexpression (SF1B); however, mutant N370S GBA exclusively decreased the $\%$ of secreted (extra/intracellular) human AS (SF1C).

Mutant N370S and WT GCase overexpression affect neither nigrostriatal dopaminergic system integrity nor AS expression in vivo

Unilateral striatal injections of GFP, WT GBA or N370S AAVs in mice led to efficient delivery of transgenes to the striatum, expression in the cortex, and retrograde transport to the substantia nigra at 8 WPI (SF2). WT GBA overexpression led to a nonsignificant increase in net cortical GCase enzyme activity (Fig 1D) but no changes in striatal dopamine levels (Fig 1E) or tyrosine hydroxylase (TH) density of dopaminergic terminals (Fig 1F). Measurements of 
total AS protein levels in the striatal, cortical, and ventral midbrain tissue did not reveal any statistically significant changes following WT GBA or N370S GBA overexpression (Fig 1G-I).

Experiment 2: GCase downregulation and human AS overexpression

The in vitro experiments in HEK293T cells showed that GCase enzymatic activity was increased two-fold in WT GBA- overexpressing cells $(p<0.0001)$, while the three mutations showed similar GCase activity levels as GFP-expressing cells (SF1A). The D409V and L444P GBA mutations showed no significant changes to intracellular or extracellular AS levels, whereas a statistically significant reduction in secretion of AS in the presence of N370S mutated plasmid of GBA was observed without a significant change in intracellular levels of AS (SF1B,C). Therefore, the N370S mutation was chosen for the in vivo experiments.

\section{Significant GCase downregulation at 8 WPI}

miR GBA-GFP and human AS expressing AAVs infected the striatum, the site of injection, as well as the cortex and were efficiently retrogradely transported to the ipsilateral substantia nigra (Fig 2A,B). miR GBA-induced GCase downregulation was determined in Neuro2A cells (Fig 2C), and then in vivo at 4 and 8 WPI. No significant GCase downregulation was observed at 4 WPI in miR GBA-GFP-injected mouse striatum (SF3). However, GCase levels decreased by approximately $40 \%$ at $8 \mathrm{WPI}$, as assessed by immunohistochemistry in the ipsilateral striatum $\left(t_{4}=3.046, p=0.0382\right)$ (Fig 4A, D). A similar magnitude of cortical GCase activity reduction was observed in miR GBA-GFP injected mice (miR treatment effect: $\left[F_{(2,25)}=9.42, p=0.0009\right]$, Fig 2E) and glucosylceramide accumulation was observed in the substantia nigra, which was reversed in miR Resc-injected mice (miR treatment effect $\left[F_{(2,53)}=25.13, p<0.0001\right]$, Fig $2 F$ ). Levels of other glycosphingolipids including sphingomyelin and psychosine were unchanged 
(SF4) and glycosylsphingosine levels were undetectable. Based on these results, further analysis of dopaminergic system integrity and AS pathology was performed at 8 WPI.

miRNA-mediated GCase downregulation and AS overexpression is accompanied by synergistic nigrostriatal neurodegeneration

Striatal dopamine (DA) levels $\left(F_{(2,25)}=3.78, p=0.037\right.$, interaction: $\left.F_{(2,25)}=3.32, p=0.053\right)$, $\mathrm{TH}$ immunostaining and $\mathrm{TH}+$ neuron stereological counts in the substantia nigra (miR treatment: $\left.F_{(2,34)}=11.08, p=0.0002\right)$ were decreased only in the miR GBA + AS group and both of these effects were reversed in the miR Resc + AS group (Fig $3 A-C$ ). The inverse relationship between GBA levels and TH expression (when combined with AS overexpression) in the substantia nigra is evident in immunofluorescent images (Fig 3D), indicating a specific synergistic neurodegenerative effect of GCase downregulation and AS overexpression.

Enhanced AS accumulation and release along the nigrostriatal axis mediated by GBA downregulation

Enhanced accumulation of human AS was evident in both the striatum and substantia nigra in the miR GBA + AS groups, while levels of AS in the miR Resc + AS group were comparable to miR CTL + AS levels (striatum: Fig 4A left, $B ; F_{(2,12)}=6.54, p=0.012$; substantia nigra: Fig $4 A$ right, $\left.C ; F_{(2,23)}=26.22, p<0.0001\right)$. Next, human AS cDNA levels were measured in the ventral midbrain. The data revealed no differences in AS cDNA expression (Fig 4D), thus precluding differences in human AS levels due to the expression of the viral transgene in the various conditions. Finally, in vivo microdialysis in the striatum revealed enhanced AS release in the miR GBA + AS group compared to miR CTL + AS and this effect was reversed in the miR Resc + AS group (Fig 4E, $\left.F_{(2,7)}=7.86, p=0.016\right)$. Increased AS expression in the miR GBA + AS group was accompanied by increased spontaneous activity measured in number of total 
rearings in the cylinder test (SF5, miR treatment: $F_{(2,59)}=10.09, p=0.0002$, AS treatment: $\left.F_{(1,59)}=4.17, p=0.046\right)$.

GCase downregulation is associated with astro- and microgliosis along the nigrostriatal axis GFAP immunostaining in the striatum revealed increased astrogliosis following miR GBA treatment and this finding was significant in the miR GBA + AS group when compared with miR CTL + AS group and reversed with miR Resc expression (Fig 5A,B; miR treatment effect: $\left.F_{(2,24)}=13.01, p=0.0001\right)$. GFAP immunostaining in the substantia nigra revealed a similar trend (Fig $5 C, D$; miR treatment effect: $F_{(2,24)}=3.95, p=0.033$ ), with increased astrogliosis in the miR GBA-treated groups. Iba1 staining in the striatum revealed significantly increased microgliosis following miR GBA treatment, regardless of AS overexpression (Fig 5E,F; miR treatment effect: $\left.F_{(2,23)}=17.15, p<0.0001\right)$, while in the substantia nigra, microgliosis was enhanced only in the miR GBA-AS group and reversed in the miR Resc - AS group (Fig 5G,H; miR treatment effect: $\left.F_{(2,24)}=6.54, p=0.0054\right)$. Overall, these data indicate that the main driver of inflammatory responses in this model, including both astrocytic and microglial activation, is the downregulation of GBA, while a synergistic effect of AS overexpression is perhaps slightly evident in the case of astrocytes.

\section{Discussion}

In an effort to develop a novel mouse model which recapitulates GBA-PD pathogenesis, where $G B A$ mutations are a risk factor but not a determinant of the disease process, our study uses viral models in vivo to assess the isolated and combined effects of modulating GBA activity and AS expression along the nigrostriatal axis. We demonstrate that neither WT nor N370S GCase overexpression alters endogenous AS levels, but that GCase 
downregulation via a microRNA results in insufficient GCase function, substrate accumulation, and neuroinflammation (astro- and microgliosis). Furthermore, the combination of GCase downregulation and human AS overexpression leads to a synergistic augmentation of AS burden and increased striatal AS release, resulting in significant nigrostriatal neurodegeneration. This double-hit model recapitulates key pathological features of PD which manifest at 8 WPI in young adult WT mice, rendering it a valuable tool for studying the underlying mechanisms of disease pathogenesis and screening of potential disease-modifying therapeutics.

Our assessment of WT and N370S GBA overexpression revealed minimal effects on AS tissue levels in the cortex and no effect on nigrostriatal dopaminergic system integrity. Mutant N370S GBA decreased secreted AS in vitro, perhaps indicating a disruption of the secretory pathway through effects of the mutant protein on the ER/Golgi/endosomal/lysosomal compartment. On the other hand, in vivo mutant N370S GBA, but not WT GBA viral expression, in the striatum of transgenic A53T AS mice had the opposite effects, enhancing extracellular AS release (24), suggesting that in vivo and cell culture-based mechanisms of AS secretion may be different. Of note, N370S heterozygosity did not affect the disease course in A30P AS mice (25). Thus, although GBA mutations alone may disrupt AS proteostasis, depending on the context, an enhanced AS burden is required to cause nigrostriatal neurodegeneration.

In our next set of experiments, we focused on the combination of miRNA-mediated GBA downregulation and human AS overexpression (miR GBA + AS). In this model, we observed a lack of significant GBA downregulation at 4 weeks, while at 8 weeks, striatal GCase was reduced by approximately 40\% (Fig.2D), similar to levels present in GBA heterozygosity patients and models $(14,26)$. Furthermore, reduced GCase expression resulted in decreased 
GCase enzyme activity, more evident in the miR GBA + AS group, although GlcCer levels were elevated in miR GBA-treated mice, regardless of AS expression. Interestingly, the miR GBA + AS group exhibited elevated levels of human AS both in the striatum and substantia nigra and enhanced striatal AS release when compared with miR CTL + AS and miR Resc+ AS groups, further supporting the hypothesis of a "toxic" synergistic interplay. Both the miR CTL + AS and miR Resc + AS groups appeared to have similar levels of human AS expression, demonstrating that reversal of the phenotype and restoration of normal GCase function by overexpression of the human GBA gene is sufficient to prevent the aberrant accumulation of AS. We confirmed that this enhanced accumulation of AS was due to the downregulation of GBA along the nigrostriatal axis and not due to variance of the viral load delivered in the striatum of the animals, as all groups had similar levels of human AS mRNA. From our findings, it is apparent that when there is a reduction in the GCase activity of neurons overexpressing AS, there is enhanced AS accumulation. AS accumulation could be facilitated by GlcCer accumulation, due to deficits in GCase activity $(21,27)$. Neuronal cultures, derived from the knock-in L444P GBA mutant mouse expressing human AS, resulted in decreased human AS degradation and subsequently, increased AS steady state levels (28). Finally, deficits in Iysosomal function and thus AS clearance may also play a role $(20,29)$, leading to an overall increase of AS's half-life. Thus, baseline AS burden is a prerequisite for a "snowball" effect to occur in the presence of lipid substrate accumulation and vice versa, reduced GCase expression/activity exerts gene dose-dependent effects on AS accumulation. It is of note that our findings here in this regard are at odds with our data in cultured neuronal SH-SY5Y cells and primary cortical neurons, where near-complete pharmacological inhibition of GCase activity did not alter the burden of AS, be it monomeric or oligomeric, endogenous or overexpressed (30). This may reflect, as above, differences between the cell culture and in 
vivo settings, but also may relate to the timing of exposure to these manipulations, which is much more prolonged in the present experiments, and the degree of accumulation of the glycolipid substrates in each case.

Heterozygous GBA1 KO mice crossed with AS BAC mice also demonstrated reduced GCase activity, however, GlcCer levels and total AS levels were unaffected while mild nigral dopaminergic cell loss and phosphorylated AS were only observed in aged (>16 month) mice (26). Moreover, heterozygous GBA1 KO mice crossed with A53T AS mice had neither a difference in GCase levels and activity nor in AS levels, even though symptom severity and lethality were accelerated (17). Taken together, unknown indirect mechanisms of GBA lossof-function and potential developmental compensatory mechanisms in transgenic mice exist that may not affect viral-mediated altered expression in adult mice. Along these lines, GCase deficiency caused by L444P heterozygosity is not itself sufficient to induce nigral cell loss, but it significantly enhances the toxic effects of AS overexpression (Ikuno et al., 2019; Osellame et al., 2013). The L444P mutation prolongs the half-life of endogenous AS and AAV-delivered human AS, thus enhancing its intraneuronal levels and promoting AS assembly (13).

Post-mortem GBA-PD brains demonstrate extensive neuroinflammation and significant loss of dopaminergic nigral neurons (31). In murine models of GBA deficiency (both transgenic and pharmacologically induced with $\mathrm{CBE}$ ), microglial activation and astrogliosis are spatially and temporally correlated with AS accumulation $(27,32,33)$ and nigrostriatal degeneration when there is a PD challenge such as MPTP (33) or AS overexpression (A53T mice) (32). Our findings support a link between GBA deficiency and enhanced glial activation and astrogliosis along the nigrostriatal axis (Fig. 4). However, excess AS accumulation and enhanced striatal release does not appear to further exacerbate this inflammatory response; rather, the synergistic effects of GBA deficiency and AS overexpression is required for full- 
blown nigrostriatal degeneration. Based on previous studies suggesting that extracellular AS can trigger an inflammatory response by increasing proinflammatory cytokines and glial activation (34-36), our results suggest that a ceiling effect may be achieved with GBA deficiency on nigrostriatal neuroinflammation. However, GBA deficiency in the presence of excess AS drives its further accumulation and deposition into the extracellular space, potentially contributing to the neurodegenerative process.

GBA-PD correlates with more severe motor phenotypes and increased risk of nonmotor manifestations, including dementia and psychosis (Gegg et al., 2012; Schöndorf et al., 2018). Interestingly, assessment of spontaneous motor activity revealed a synergistic enhancement of locomotor activity with GBA downregulation and human AS overexpression, reminiscent of psychosis, as we have previously reported in human AS BAC transgenic rats (23). Similar findings were observed in AS BAC transgenic mice crossed with $G B A$ heterozygous mice (26). Interestingly, no unilateral impairments were observed, but it is possible that the synergistic effects of GBA downregulation and AS overexpression, on excess AS accumulation and striatal release, over-ride potential subtle motor impairments.

\section{Conclusions}

The present data support a loss-of-function association of GBA mutations in PD and suggest that GBA-PD is more likely to develop if AS burden is increased. Such an increase could concomitantly occur through genetic or epigenetic regulation, and could be further driven by GBA partial deficiency, as demonstrated here, leading to the PD phenotype manifestation, once a threshold is crossed. Such models are vital to study the pathogenic mechanisms involved in GBA-associated nigrostriatal neurodegeneration in PD. Most importantly, 
understanding such mechanisms may lead to novel therapeutic targets for GBA-PD, but also potentially, more broadly in sporadic PD.

This novel PD model has several advantages over current models including construct validity (genetics and pathology) and the manifestation of a neurodegenerative phenotype within a short time frame ( 2 months); ideal for assessing both potential preventative and disease-modifying therapeutic strategies. Therapeutic development efforts are currently focused on boosting GCase activity, reducing substrate accumulation or aberrant AS. The propensity of GCase deficiency to lower the threshold for pathological AS accumulation and subsequently, promote its release into the extracellular space, thus spreading pathology, supports the therapeutic potential of AS immunotherapy. On the other hand, in a recent phase 2 study, venglustat, a glucosylceramide synthase inhibitor aimed at reducing glycolipid substrate accumulation, failed to demonstrate efficacy in improving the Unified Parkinson's Disease Rating Scale score in GBA-PD patients. This major therapeutic disappointment, however, demonstrates GBA's complex role in PD beyond substrate accumulation and highlights the importance and urgency of deciphering novel AS-GBA-based pathway interactions at the molecular, cellular, and systems level in robust models of GBA-linked PD.

\section{List of abbreviations}

4-MU 4-methylumbelliferyl- $\beta$-d-glucopyranoside

AAV adeno-associated virus

AS alpha-synuclein

CBE conduritol-B-epoxide

Cer ceramide

CTL control 

DA dopamine
DAT dopamine transporter
GCase beta-glucocerebrosidase
GFP green fluorescent protein
GlcCer glucosylceramide
GlcSph glucosylsphingosine
miR microRNA
PFA paraformaldehyde
rAd recombinant adenovirus
TH tyrosine hydroxylase
WPI weeks post-injection
WT wild-type

\section{Declarations}

\section{Availability of data and materials}

The datasets used and/or analysed during the current study are available from the corresponding author on reasonable request.

\section{Competing Interests}

A.P., G.N., E.K., M.B., K.V., M.X., declare that they have no competing interests. C.V. and S.P.S are employees and stockholders of Sanofi. L.S. has served on Advisory Boards for Abbvie, Roche and Innovis and has received honoraria from Abbvie and Sanofi for participation in Satellite Symposia. 


\section{Funding}

This research was supported by the Hellenic Foundation for Research and Innovation (H.F.R.I. postdoctoral grant (1855), awarded to A.P.), the General Secretariat for Research and Innovation (G.S.R.I. "Excellence" (ARISTEIA II) grant, awarded to K.V.), and an EU, FP7HEALTH.2013.1.2-1 European Program ("MULTISYN" (602646), awarded to L.S. as a Collaborator). Funding sources were not involved in study design; in the collection, analysis and interpretation of data; in the writing of the report; or in the decision to submit the article for publication.

\section{Authors' Contributions}

AP designed and funded the study, performed and supervised experiments, and wrote the manuscript; GN performed in vitro experiments, EF performed immunohistochemistry experiments and data analysis; MN performed stereological counts and immunohistochemistry experiments; CV performed glycosphingolipid analysis and edited the manuscript; $\mathrm{MB}$ performed immunohistochemistry experiments: SPS provided viruses, supervised experiments, and edited the manuscript; MX designed the study and edited the manuscript; KV funded and supervised the study; LS funded and supervised the study and revised the manuscript. All authors read and approved the final manuscript.

\section{Acknowledgments}

We would like to acknowledge the technical support of the Animal Housing facility personnel and Dr. Stamatis Pagakis and Eleni Rigana of the Bioimaging Unit at BRFAA. 



\section{References}

1: Gegg ME, Verona G, Schapira AHV. Glucocerebrosidase deficiency promotes release of $\alpha$-synuclein fibrils from cultured neurons. Hum Mol Genet. 2020 Jun 27;29(10):1716-1728. doi: 10.1093/hmg/ddaa085. PMID: 32391886; PMCID: PMC7322566.

2: Lerche S, Wurster I, Roeben B, Zimmermann M, Riebenbauer B, Deuschle C, Hauser AK, Schulte C, Berg D, Maetzler W, Waniek K, Lachmann I, Liepelt-Scarfone I, Gasser T, Brockmann K. Parkinson's Disease: Glucocerebrosidase 1 Mutation Severity Is Associated with CSF Alpha-Synuclein Profiles. Mov Disord. 2020 Mar;35(3):495-499. doi: 10.1002/mds.27884. Epub 2019 Oct 30. PMID: 31670439.

3: Aflaki E, Stubblefield BK, McGlinchey RP, McMahon B, Ory DS, Sidransky E. A characterization of Gaucher iPS-derived astrocytes: Potential implications for Parkinson's disease. Neurobiol Dis. 2020 Feb;134:104647. doi:

10.1016/j.nbd.2019.104647. Epub 2019 Nov 10. PMID: 31669751; PMCID: PMC6980699.

4: Yang SY, Gegg M, Chau D, Schapira A. Glucocerebrosidase activity, cathepsin D and monomeric $\alpha$-synuclein interactions in a stem cell derived neuronal model of a PD associated GBA1 mutation. Neurobiol Dis. 2020 Feb;134:104620. doi: 10.1016/j.nbd.2019.104620. Epub 2019 Oct 18. PMID: 31634558; PMCID: PMC6983928. 
10.1016/j.tins.2019.05.010. Epub 2019 Jul 6. PMID: 31288942.

6: Bieri G, Brahic M, Bousset L, Couthouis J, Kramer NJ, Ma R, Nakayama L, Monbureau M, Defensor E, Schüle B, Shamloo M, Melki R, Gitler AD. LRRK2 modifies a-syn pathology and spread in mouse models and human neurons. Acta Neuropathol. 2019 Jun;137(6):961-980. doi: 10.1007/s00401-019-01995-0. Epub 2019 Mar 29. PMID: 30927072; PMCID: PMC6531417.

7: Ikuno M, Yamakado H, Akiyama H, Parajuli LK, Taguchi K, Hara J, Uemura N, Hatanaka Y, Higaki K, Ohno K, Tanaka M, Koike M, Hirabayashi Y, Takahashi R. GBA haploinsufficiency accelerates alpha-synuclein pathology with altered lipid metabolism in a prodromal model of Parkinson's disease. Hum Mol Genet. 2019 Jun 1;28(11):1894-1904. doi: 10.1093/hmg/ddz030. PMID: 30689867.

8: Maor G, Rapaport D, Horowitz M. The effect of mutant GBA1 on accumulation and aggregation of $\alpha$-synuclein. Hum Mol Genet. 2019 Jun 1;28(11):1768-1781. doi: 10.1093/hmg/ddz005. PMID: 30615125.

9: Mus L, Siani F, Giuliano C, Ghezzi C, Cerri S, Blandini F. Development and biochemical characterization of a mouse model of Parkinson's disease bearing defective glucocerebrosidase activity. Neurobiol Dis. 2019 Apr;124:289-296. doi: 10.1016/j.nbd.2018.12.001. Epub 2018 Dec 4. PMID: 30521842.

10: Kim D, Hwang H, Choi S, Kwon SH, Lee S, Park JH, Kim S, Ko HS. D409H GBA1 
mutation accelerates the progression of pathology in A53T $\alpha$-synuclein transgenic mouse model. Acta Neuropathol Commun. 2018 Apr 27;6(1):32. doi:

10.1186/s40478-018-0538-9. PMID: 29703245; PMCID: PMC5923019.

11: Kim S, Yun SP, Lee S, Umanah GE, Bandaru VVR, Yin X, Rhee P, Karuppagounder SS, Kwon SH, Lee H, Mao X, Kim D, Pandey A, Lee G, Dawson VL, Dawson TM, Ko HS. GBA1 deficiency negatively affects physiological $\alpha$-synuclein tetramers and related multimers. Proc Natl Acad Sci U S A. 2018 Jan 23;115(4):798-803. doi: 10.1073/pnas.1700465115. Epub 2018 Jan 8. PMID: 29311330; PMCID: PMC5789900.

12: Papadopoulos VE, Nikolopoulou G, Antoniadou I, Karachaliou A, Arianoglou G, Emmanouilidou E, Sardi SP, Stefanis L, Vekrellis K. Modulation of $\beta$-glucocerebrosidase increases $\alpha$-synuclein secretion and exosome release in mouse models of Parkinson's disease. Hum Mol Genet. 2018 May 15;27(10):1696-1710. doi: 10.1093/hmg/ddy075. PMID: 29547959.

13: Migdalska-Richards A, Wegrzynowicz M, Rusconi R, Deangeli G, Di Monte DA, Spillantini MG, Schapira AHV. The L444P Gba1 mutation enhances alpha-synuclein induced loss of nigral dopaminergic neurons in mice. Brain. 2017 Oct 1;140(10):2706-2721. doi: 10.1093/brain/awx221. PMID: 28969384; PMCID: PMC5841155.

14: Taguchi YV, Liu J, Ruan J, Pacheco J, Zhang X, Abbasi J, Keutzer J, Mistry PK, Chandra SS. Glucosylsphingosine Promotes $\alpha$-Synuclein Pathology in Mutant GBA-Associated Parkinson's Disease. J Neurosci. 2017 Oct 4;37(40):9617-9631. 
doi: 10.1523/JNEUROSCI.1525-17.2017. Epub 2017 Aug 28. PMID: 28847804; PMCID: PMC5628407.

15: Parnetti L, Paciotti S, Eusebi P, Dardis A, Zampieri S, Chiasserini D, Tasegian A, Tambasco N, Bembi B, Calabresi P, Beccari T. Cerebrospinal fluid $\beta$-glucocerebrosidase activity is reduced in parkinson's disease patients. Mov Disord. 2017 Oct;32(10):1423-1431. doi: 10.1002/mds.27136. Epub 2017 Aug 26. PMID: 28843015.

16: Tayebi N, Parisiadou L, Berhe B, Gonzalez AN, Serra-Vinardell J, Tamargo RJ, Maniwang E, Sorrentino Z, Fujiwara H, Grey RJ, Hassan S, Blech-Hermoni YN, Chen C, McGlinchey R, Makariou-Pikis C, Brooks M, Ginns EI, Ory DS, Giasson BI, Sidransky E. Glucocerebrosidase haploinsufficiency in A53T $\alpha$-synuclein mice impacts disease onset and course. Mol Genet Metab. 2017 Dec;122(4):198-208. doi: 10.1016/j.ymgme.2017.11.001. Epub 2017 Nov 21. PMID: 29173981; PMCID: PMC6007972.

17: Burbulla LF, Song P, Mazzulli JR, Zampese E, Wong YC, Jeon S, Santos DP, Blanz J, Obermaier CD, Strojny C, Savas JN, Kiskinis E, Zhuang X, Krüger R, Surmeier DJ, Krainc D. Dopamine oxidation mediates mitochondrial and lysosomal dysfunction in Parkinson's disease. Science. 2017 Sep 22;357(6357):1255-1261. doi: 10.1126/science.aam9080. Epub 2017 Sep 7. PMID: 28882997; PMCID: PMC6021018. 
18: Dopeso-Reyes IG, Sucunza D, Rico AJ, Pignataro D, Marín-Ramos D, Roda E, Rodríguez-Pérez Al, Labandeira-García JL, Lanciego JL. Glucocerebrosidase expression patterns in the non-human primate brain. Brain Struct Funct. 2018 Jan;223(1):343-355. doi: 10.1007/s00429-017-1504-1. Epub 2017 Aug 23. PMID: 28835999; PMCID: PMC5772150.

19: Soria FN, Engeln M, Martinez-Vicente M, Glangetas C, López-González MJ, Dovero S, Dehay B, Normand E, Vila M, Favereaux A, Georges F, Lo Bianco C, Bezard E, Fernagut PO. Glucocerebrosidase deficiency in dopaminergic neurons induces microglial activation without neurodegeneration. Hum Mol Genet. 2017 Jul 15;26(14):2603-2615. doi: 10.1093/hmg/ddx120. PMID: 28520872.

20: Aflaki E, Westbroek W, Sidransky E. The Complicated Relationship between Gaucher Disease and Parkinsonism: Insights from a Rare Disease. Neuron. 2017 Feb 22;93(4):737-746. doi: 10.1016/j.neuron.2017.01.018. PMID: 28231462; PMCID: PMC5327952.

21: Wong YC, Krainc D. Lysosomal trafficking defects link Parkinson's disease with Gaucher's disease. Mov Disord. 2016 Nov;31(11):1610-1618. doi: 10.1002/mds.26802. Epub 2016 Sep 13. PMID: 27619775; PMCID: PMC5957289.

22: Mazzulli JR, Zunke F, Tsunemi T, Toker NJ, Jeon S, Burbulla LF, Patnaik S, Sidransky E, Marugan JJ, Sue CM, Krainc D. Activation of $\beta$-Glucocerebrosidase Reduces Pathological $\alpha$-Synuclein and Restores Lysosomal Function in Parkinson's 
Patient Midbrain Neurons. J Neurosci. 2016 Jul 20;36(29):7693-706. doi:

10.1523/JNEUROSCI.0628-16.2016. PMID: 27445146; PMCID: PMC4951575.

23: Fernandes HJ, Hartfield EM, Christian HC, Emmanoulidou E, Zheng Y, Booth H, Bogetofte H, Lang C, Ryan BJ, Sardi SP, Badger J, Vowles J, Evetts S, Tofaris GK, Vekrellis K, Talbot K, Hu MT, James W, Cowley SA, Wade-Martins R. ER Stress and Autophagic Perturbations Lead to Elevated Extracellular $\alpha$-Synuclein in GBA-N370S Parkinson's iPSC-Derived Dopamine Neurons. Stem Cell Reports. 2016 Mar 8;6(3):342-56. doi: 10.1016/j.stemcr.2016.01.013. Epub 2016 Feb 18. PMID: 26905200; PMCID: PMC4788783.

24: Rocha EM, Smith GA, Park E, Cao H, Brown E, Hayes MA, Beagan J, McLean JR, Izen SC, Perez-Torres E, Hallett PJ, Isacson O. Glucocerebrosidase gene therapy prevents $\alpha$-synucleinopathy of midbrain dopamine neurons. Neurobiol Dis. 2015 Oct;82:495-503. doi: 10.1016/j.nbd.2015.09.009. Epub 2015 Sep 25. PMID: 26392287.

25: Du TT, Wang L, Duan CL, Lu LL, Zhang JL, Gao G, Qiu XB, Wang XM, Yang H. GBA deficiency promotes SNCA/ $\alpha$-synuclein accumulation through autophagic inhibition by inactivated PPP2A. Autophagy. 2015;11(10):1803-20. doi: 10.1080/15548627.2015.1086055. PMID: 26378614; PMCID: PMC4824589.

26: Bae EJ, Yang NY, Lee C, Lee HJ, Kim S, Sardi SP, Lee SJ. Loss of glucocerebrosidase 1 activity causes lysosomal dysfunction and $\alpha$-synuclein aggregation. Exp Mol Med. 2015 Mar 
27;47(3):e153. doi: 10.1038/emm.2014.128. Erratum in: Exp Mol Med. 2015;47:e188. PMID: 25813221; PMCID: PMC4351412.

27: Fishbein I, Kuo YM, Giasson BI, Nussbaum RL. Augmentation of phenotype in a transgenic Parkinson mouse heterozygous for a Gaucher mutation. Brain. 2014 Dec;137(Pt 12):3235-47. doi: 10.1093/brain/awu291. Epub 2014 Oct 27. PMID: 25351739; PMCID: PMC4240298.

28: Rothaug M, Zunke F, Mazzulli JR, Schweizer M, Altmeppen H, Lüllmann-Rauch R, Kallemeijn WW, Gaspar P, Aerts JM, Glatzel M, Saftig P, Krainc D, Schwake M, Blanz J. LIMP-2 expression is critical for $\beta$-glucocerebrosidase activity and $\alpha$-synuclein clearance. Proc Natl Acad Sci U S A. 2014 Oct 28;111(43):15573-8. doi: 10.1073/pnas.1405700111. Epub 2014 Oct 14. PMID: 25316793; PMCID: PMC4217458.

29: Bae EJ, Yang NY, Song M, Lee CS, Lee JS, Jung BC, Lee HJ, Kim S, Masliah E, Sardi SP, Lee SJ. Glucocerebrosidase depletion enhances cell-to-cell transmission of $\alpha$-synuclein. Nat Commun. 2014 Aug 26;5:4755. doi: 10.1038/ncomms5755. PMID: 25156829; PMCID: PMC4452288.

30: Siebert M, Sidransky E, Westbroek W. Glucocerebrosidase is shaking up the synucleinopathies. Brain. 2014 May;137(Pt 5):1304-22. doi: 10.1093/brain/awu002. Epub 2014 Feb 14. PMID: 24531622; PMCID: PMC3999712. 
31: Murphy KE, Gysbers AM, Abbott SK, Tayebi N, Kim WS, Sidransky E, Cooper A, Garner B, Halliday GM. Reduced glucocerebrosidase is associated with increased a-synuclein in sporadic Parkinson's disease. Brain. 2014 Mar;137(Pt 3):834-48. doi: 10.1093/brain/awt367. Epub 2014 Jan 28. PMID: 24477431; PMCID: PMC3927701.

32: Tsunemi T, Krainc D. Zn ${ }^{2+}$ dyshomeostasis caused by loss of ATP13A2/PARK9 leads to lysosomal dysfunction and alpha-synuclein accumulation. Hum Mol Genet. 2014 Jun 1;23(11):2791-801. doi: 10.1093/hmg/ddt572. Epub 2013 Dec 13. PMID: 24334770; PMCID: PMC4014186.

33: van Dijk KD, Persichetti E, Chiasserini D, Eusebi P, Beccari T, Calabresi P, Berendse HW, Parnetti L, van de Berg WD. Changes in endolysosomal enzyme activities in cerebrospinal fluid of patients with Parkinson's disease. Mov Disord. 2013 Jun;28(6):747-54. doi: 10.1002/mds.25495. Epub 2013 May 27. PMID: 23712522.

34: Dermentzaki G, Dimitriou E, Xilouri M, Michelakakis H, Stefanis L. Loss of $\beta$-glucocerebrosidase activity does not affect alpha-synuclein levels or Iysosomal function in neuronal cells. PLoS One. 2013 Apr 8;8(4):e60674. doi: 10.1371/journal.pone.0060674. PMID: 23580063; PMCID: PMC3620326.

35: Schapira AH, Gegg ME. Glucocerebrosidase in the pathogenesis and treatment of Parkinson disease. Proc Natl Acad Sci U S A. 2013 Feb 26;110(9):3214-5. doi: 10.1073/pnas.1300822110. Epub 2013 Feb 14. PMID: 23412333; PMCID: PMC3587236. 
36: Gegg ME, Burke D, Heales SJ, Cooper JM, Hardy J, Wood NW, Schapira AH. Glucocerebrosidase deficiency in substantia nigra of parkinson disease brains. Ann Neurol. 2012 Sep;72(3):455-63. doi: 10.1002/ana.23614. PMID: 23034917; PMCID: PMC3638323.

37: Sardi SP, Singh P, Cheng SH, Shihabuddin LS, Schlossmacher MG. Mutant GBA1 expression and synucleinopathy risk: first insights from cellular and mouse models. Neurodegener Dis. 2012;10(1-4):195-202. doi: 10.1159/000335038. Epub 2012 Feb 9. PMID: 22327140.

38: Fernagut PO. Links between glucocerebrosidase and alpha-synuclein revealed. Mov Disord. 2011 Oct;26(12):2177. doi: 10.1002/mds.23985. PMID: 22319791.

39: Sardi SP, Clarke J, Kinnecom C, Tamsett TJ, Li L, Stanek LM, Passini MA, Grabowski GA, Schlossmacher MG, Sidman RL, Cheng SH, Shihabuddin LS. CNS expression of glucocerebrosidase corrects alpha-synuclein pathology and memory in a mouse model of Gaucher-related synucleinopathy. Proc Natl Acad Sci U S A. 2011 Jul 19;108(29):12101-6. doi: 10.1073/pnas.1108197108. Epub 2011 Jul 5. PMID: 21730160; PMCID: PMC3141921.

40: Mazzulli JR, Xu YH, Sun Y, Knight AL, McLean PJ, Caldwell GA, Sidransky E, Grabowski GA, Krainc D. Gaucher disease glucocerebrosidase and $\alpha$-synuclein form a bidirectional pathogenic loop in synucleinopathies. Cell. $2011 \mathrm{Jul}$ 
8;146(1):37-52. doi: 10.1016/j.cell.2011.06.001. Epub 2011 Jun 23. PMID: 21700325; PMCID: PMC3132082. 


\section{Figure legends}

Figure 1. In vivo viral overexpression of GFP, wild-type (WT) and mutant (N370S) GBA. In vivo unilateral striatal overexpression of WT GBA or N370S GBA (vs. GFP) did not affect cortical GCase enzyme ipsilateral/contralateral activity (ipsi(lateral)/contra(lateral) activity); although there was a definite trend for an increase with WT GBA (A), striatal dopamine (DA) levels (expressed as $\mu \mathrm{g} / \mathrm{g}$ wet tissue) (B), striatal tyrosine hydroxylase ( $\mathrm{TH}$ ) intensity (measured in arbitrary units (au) ipsi/contra) (C), total AS levels (ipsi/contra) in the striatum (D), ventral midbrain (E), and cortex (F) as measured by Western immunoblotting (top panels: quantification of AS (measured with the Syn1 antibody and normalized to $\beta$-actin levels, expressed ipsi/contra; bottom panels: immunoblots of $\mathrm{AS}($ at $17 \mathrm{kDa})$ and $\beta$-actin $(40 \mathrm{kDa}))$.

Figure 2. In vivo microRNA-mediated downregulation of GBA (miR GBA) +/- human $\alpha$-synuclein (AS) in the striatum decreased GCase levels and activity and increased accumulation of glucosylceramide. Representative immunofluorescent images in the ipsi(lateral) (injected; top panel) vs. contra(lateral) (non-injected; bottom panel) hemisphere of 2 month-old wild-type mice 8 weeks post-injection (WPI) of microRNA (miR) GBA-GFP (green)-injected downregulation of GBA (red) in the striatum, cortex, and substantia nigra (clockwise); dopaminergic terminals (striatum) and cell bodies (substantia nigra) are indicated in pseudocolor with tyrosine hydroxylase (TH) antibody; scale bar: $25 \mu \mathrm{m}$; (A). Overexpression of human AS demonstrated with the 211 antibody (211 human (hu AS), blue) in dopamine transporter- (DAT; red) expressing striatal dopaminergic terminals (left) and cell bodies of the substantia nigra (right and top (merged image of nigral neuron at $63 x$ magnification, 2x digital zoom); scale bar: $40 \mu \mathrm{m}$; (B). Western immunoblots demonstrating downregulation ( $60 \%$ ) of glucocerebrosidase (GCase) protein in Neuro2A cells overexpressing miR GBA vs. GFP and control (CTL) conditions with $\beta$-actin as a loading control (C); quantification). Quantification of in vivo downregulation ( $\sim 40 \%)$ in miR GBA vs. miR CTL- injected mice cortices (mean GCase intensity (masked red) in GFP+ (green) cells) $(p=0.038)(D)$. Measurement of GCase activity (net GCase activity ipsi/contra) revealed a statistically significant (treatment effect: $p=0.0009$ ) decrease in miR GBA + AS-injected mice vs. miR CTL +/- AS and miR rescue (miR Resc)-injected mice had similar levels to $\mathrm{miR} C T L$, regardless of $A S$ overexpression (E). The ratio of glucosylceramide to ceramide (GlcCer/Cer; ipsi/contra) was elevated in miR GBA-injected (treatment effect: $\mathrm{p}<0.0001)$ vs. miR CTL- and miR Resc-injected mice. ${ }^{*} \mathrm{p}<0.05,{ }^{*} \mathrm{p}<0.001,{ }^{* * *} \mathrm{p}<0.0001$. (F). 
Figure 3. MicroRNA-mediated downregulation of GBA (miR GBA) in combination with human $\alpha$-synuclein (AS) overexpression leads to dopaminergic nigrostriatal neurodegeneration. Unilateral injection of GFP-miR GBA + human AS (miR GBA + AS) in the striatum demonstrates: reduced striatal dopamine (DA) levels ((ipsi)lateral vs. (contra)lateral) compared with miR control $+A S(m i R C T L+A S)(p=0.047)$ and miR rescue + AS (miR Resc $+A S)$ $(p=0.027)(A)$; decreased tyrosine hydroxylase-positive $(\mathrm{TH}+)$ neurons in the substantia nigra on the (ipsi)lateral side of miR GBA + AS-injected mice as depicted in the representative images (10x) (B); quantification of stereological counts (\% contra), demonstrates the same decrease compared with miR CTL $+/-$ AS $(p=0.021$, 0.0061 , respectively) and $\operatorname{miR} \operatorname{Resc}+/-\operatorname{AS}(p=0.0033,0.0037$, respectively) (C); and representative immunofluorescent images in the substantia nigra of the ipsi(lateral) (injected; top panel) vs. contra(lateral) (non-injected; bottom panel) hemisphere of miRNA GBA-GFP (green) and AS-injected 2 month old mice depicting downregulation of GBA (red) in TH+ cell bodies (pseudocolor) and merged images with DAPI nuclear staining (blue) (D); left panels 10x (scale bar: $100 \mu \mathrm{m}$ ), right panels 40x (scale bar: $25 \mu \mathrm{m}$ ); ${ }^{*} p<0.05, * * p<0.001$.

Figure 4. microRNA-mediated GBA (miR GBA) downregulation enhances human $\alpha$-synuclein (AS) expression and release. Representative immunofluorescent images of human AS $(211$, red) staining in miR control (miR CTL)-, miR GBA- and miR rescue GBA (miR Resc)-injected in combination with human AS (+AS) in the striatum (left panel) and substantia nigra (right panel) with dopaminergic terminals and cell bodies, respectively, stained with tyrosine hydroxylase (TH, pseudo color) (A) (scale bar: $100 \mu \mathrm{m})$; quantification revealed a statistically significant increase in human AS expression following miR GBA + AS treatment in the striatum $(p=0.012)(B)$; and in the substantia nigra $(p<0.0001)(C)$ compared to miR $C T L+A S$ and these effects were reversed in the miR Resc + AS group; cDNA levels of human AS, measured with qPCR (fold change) in ipsilateral vs. contralateral ventral midbrain tissue of the same mice, were not altered between the different treatment groups (D); in vivo microdialysis revealed enhanced extracellular AS release in the striatum of miR GBA + AS-injected mice compared to miR CTL + AS-injected mice and these effects were reversed in the miR Resc + AS group $(E) .{ }^{*} p<0.05$, $* * \mathrm{p}<0.001$. 
Figure 5. microRNA (miR)-mediated GBA (miR GBA) downregulation in the striatum induces astro- and microgliosis along the nigrostriatal axis. Representative immunofluorescent images of GFAP (marker for astrocytes, left panels) or AIF1/Iba1 (marker for microglia, right panels), DAPI (nuclear staining, blue) and merged images (DAPI/GFAP or DAPI/Iba1, respectively) in the striatum (upper panels) and substantia nigra (lower panels) of mice injected with miR control (miR CTL), miR GBA or miR rescue (miR Resc) (A) (scale bar: $25 \mu \mathrm{m}$ ). Quantification of GFAP intensity (expressed in arbitrary units (AU)) demonstrated increased expression in the mir GBA + $\alpha$-synuclein (miR GBA + AS) group vs. miR CTL + AS and miR Resc +/- AS ( $p=0.0001)(B)$ in the striatum and the same trend persisted in the substantia nigra ( $p=0.033$, no post hoc differences) (C); quantification of Iba1 intensity (expressed in $\mathrm{AU}$ ) revealed increased expression in miR GBA +/- AS compared to miR CTL +/- AS groups and effective reversal in miR Resc +/- AS groups $(p<0.0001)$ in the striatum (D); in the substantia nigra, Iba1 expression was increased in the miR GBA - AS group vs. miR Resc - AS group $(p=0.0054)(E) .{ }^{*} p<0.05$, $* * p<0.001$. 


\section{Figures}

A Cortical GCase Enzyme Activity

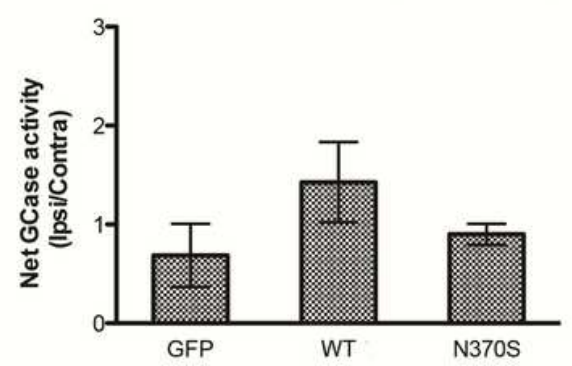

D
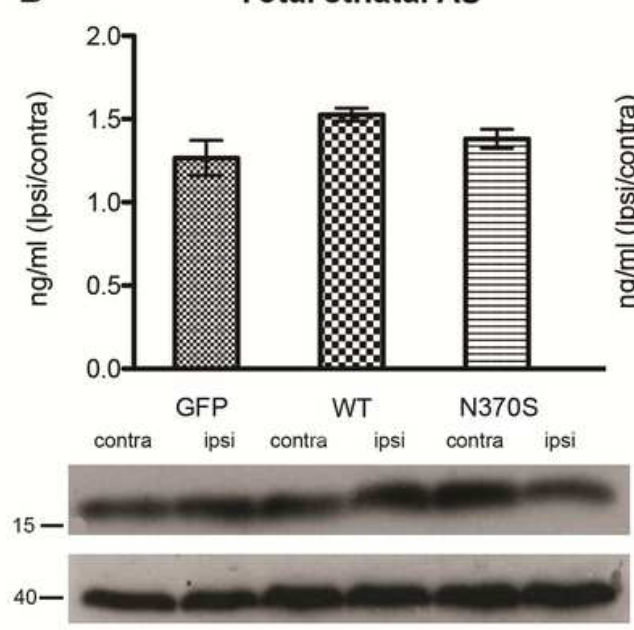

B

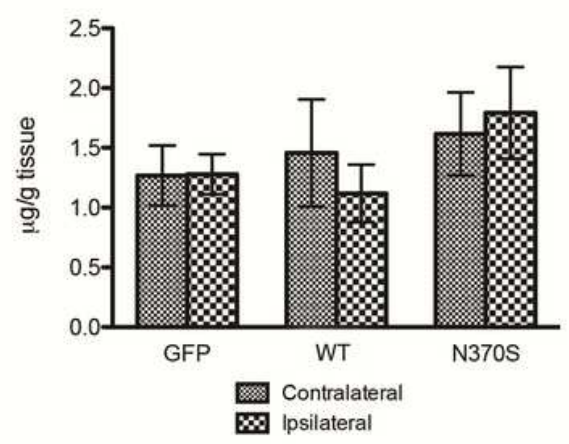

E Total AS in the ventral midbrain $F$

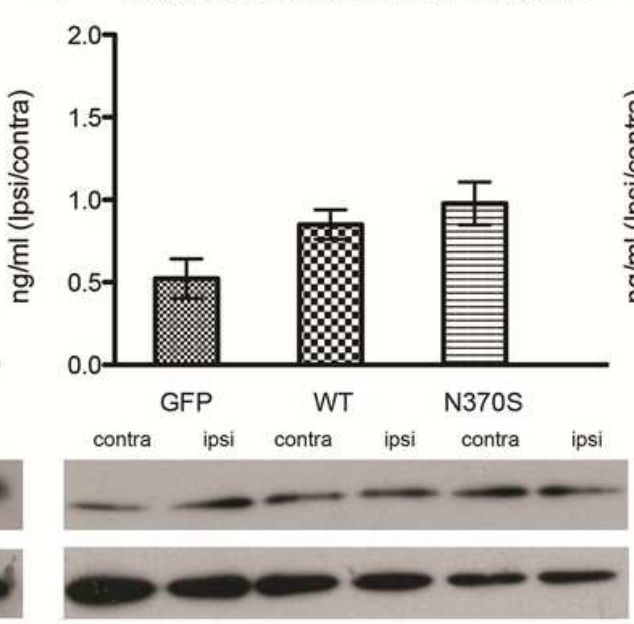

\section{Striatal TH densitometry}

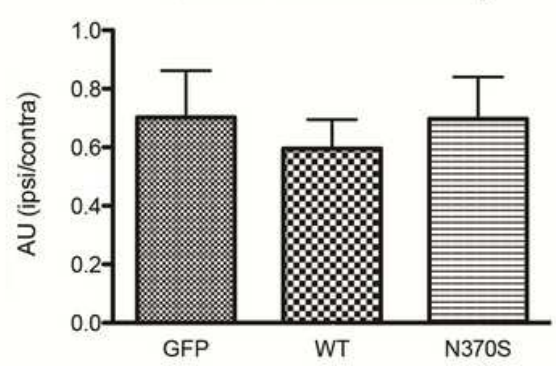

Total cortical AS

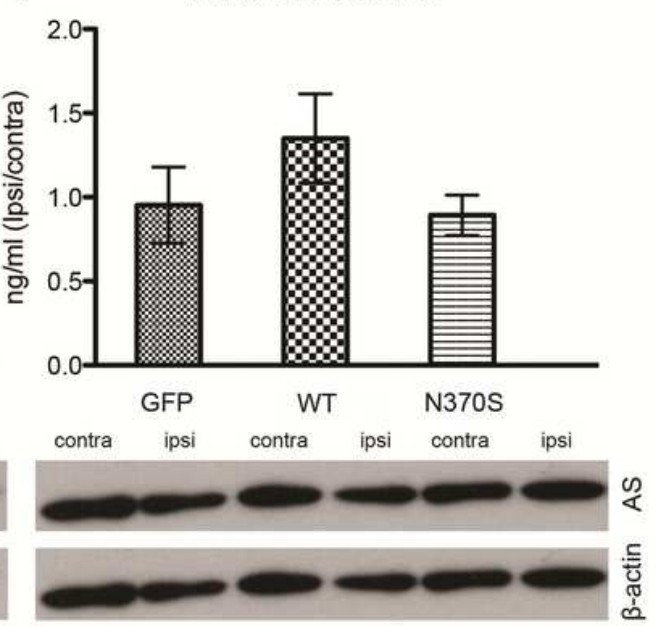

\section{Figure 1}

In vivo viral overexpression of GFP, wild-type (WT) and mutant (N370S) GBA. In vivo unilateral striatal overexpression of WT GBA or N370S GBA (vs. GFP) did not affect cortical GCase enzyme ipsilateral/contralateral activity (ipsi(lateral)/contra(lateral) activity); although there was a definite trend for an increase with WT GBA (A), striatal dopamine (DA) levels (expressed as $\mu \mathrm{g} / \mathrm{g}$ wet tissue) (B), striatal tyrosine hydroxylase (TH) intensity (measured in arbitrary units (au) ipsi/contra) (C), total AS levels (ipsi/contra) in the striatum (D), ventral midbrain (E), and cortex (F) as measured by Western immunoblotting (top panels: quantification of AS (measured with the Syn1 antibody and normalized to $\beta$ actin levels, expressed ipsi/contra; bottom panels: immunoblots of $A S$ (at $17 \mathrm{kDa})$ and $\beta$-actin (40 kDa)). 
A STRIATUM
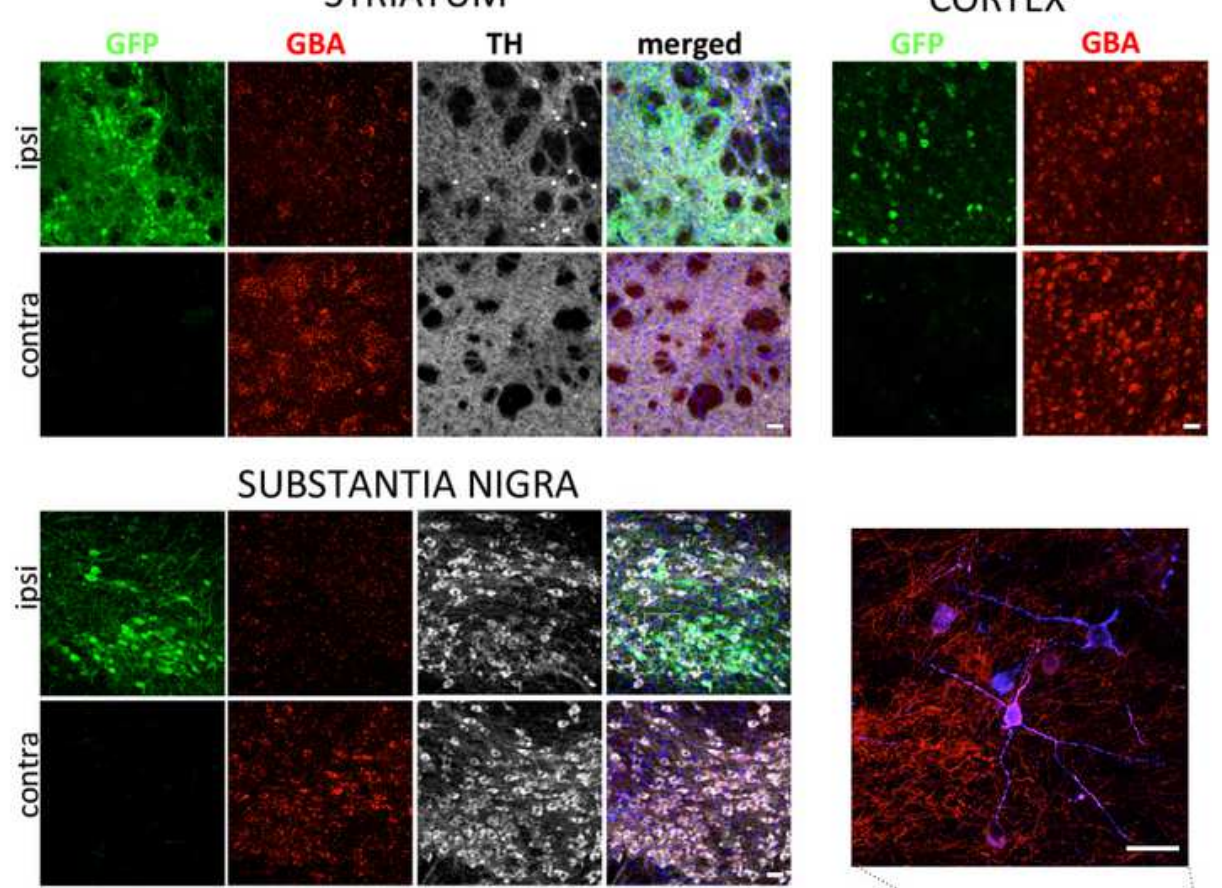

SUBSTANTIA NIGRA

B
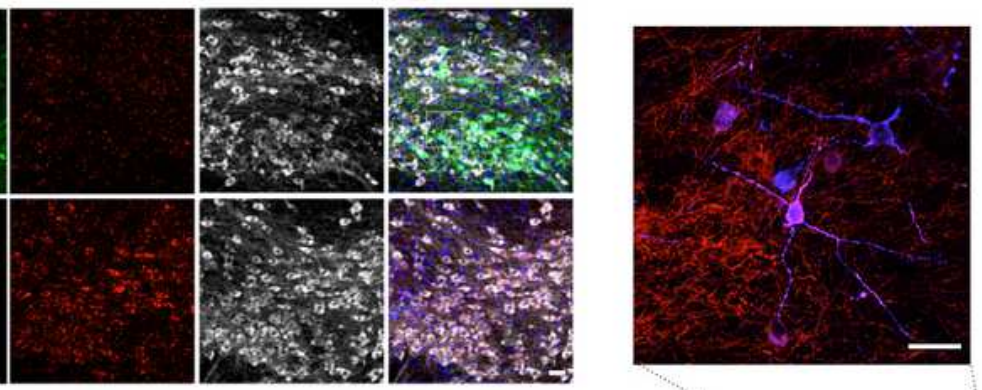

STRIATUM

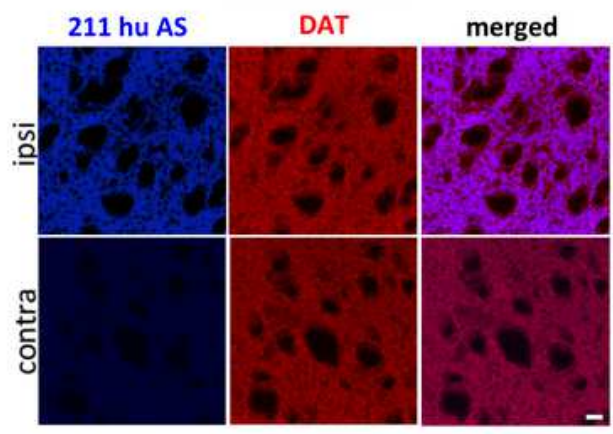

SUBSTANTIA NIGRA

211 hu AS

DAT

merged
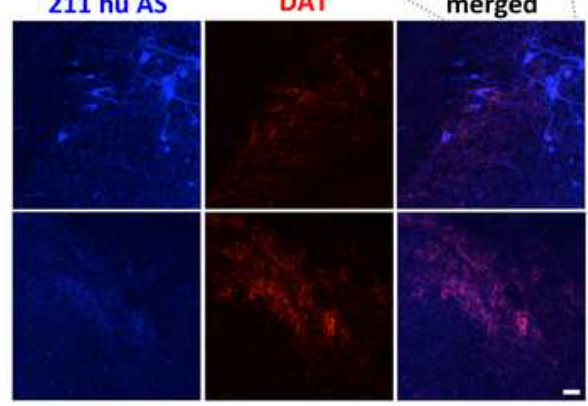

C
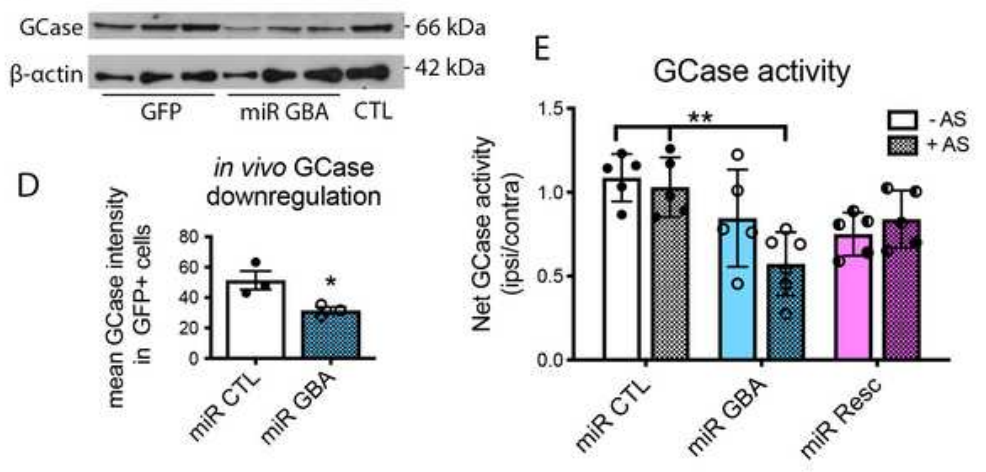

F GlcCer/Cer

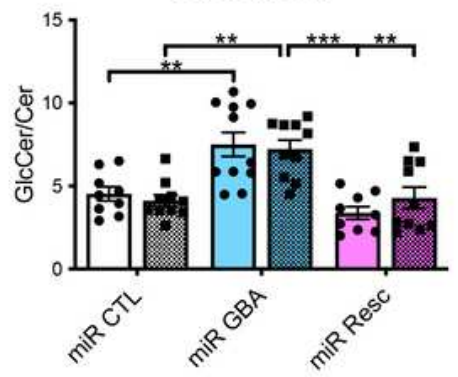

Figure 2

In vivo microRNA-mediated downregulation of GBA (miR GBA) +/- human a-synuclein (AS) in the striatum decreased GCase levels and activity and increased accumulation of glucosylceramide. Representative immunofluorescent images in the ipsi(lateral) (injected; top panel) vs. contra(lateral) (non-injected; bottom panel) hemisphere of 2 month-old wild-type mice 8 weeks post-injection (WPI) of microRNA (miR) GBA-GFP (green)-injected downregulation of GBA (red) in the striatum, cortex, and substantia nigra 
(clockwise); dopaminergic terminals (striatum) and cell bodies (substantia nigra) are indicated in pseudocolor with tyrosine hydroxylase (TH) antibody; scale bar: $25 \mu \mathrm{m}$; (A). Overexpression of human AS demonstrated with the 211 antibody (211 human (hu AS), blue) in dopamine transporter- (DAT; red) expressing striatal dopaminergic terminals (left) and cell bodies of the substantia nigra (right and top (merged image of nigral neuron at $63 x$ magnification, 2x digital zoom); scale bar: $40 \mu \mathrm{m}$; (B). Western immunoblots demonstrating downregulation ( $60 \%)$ of glucocerebrosidase (GCase) protein in Neuro2A cells overexpressing miR GBA vs. GFP and control (CTL) conditions with $\beta$-actin as a loading control (C); quantification). Quantification of in vivo downregulation ( 40\%) in miR GBA vs. miR CTL- injected mice cortices (mean GCase intensity (masked red) in GFP+ (green) cells) $(p=0.038)$ (D). Measurement of GCase activity (net GCase activity ipsi/contra) revealed a statistically significant (treatment effect: $p=0.0009$ ) decrease in miR GBA + AS-injected mice vs. miR CTL +/- AS and miR rescue (miR Resc)injected mice had similar levels to miR CTL, regardless of AS overexpression (E). The ratio of glucosylceramide to ceramide (GlcCer/Cer; ipsi/contra) was elevated in miR GBA-injected (treatment effect: $p<0.0001)$ vs. miR CTL- and miR Resc-injected mice. ${ }^{*} p<0.05,{ }^{* *} p<0.001$, ${ }^{* *} p<0.0001$. (F).
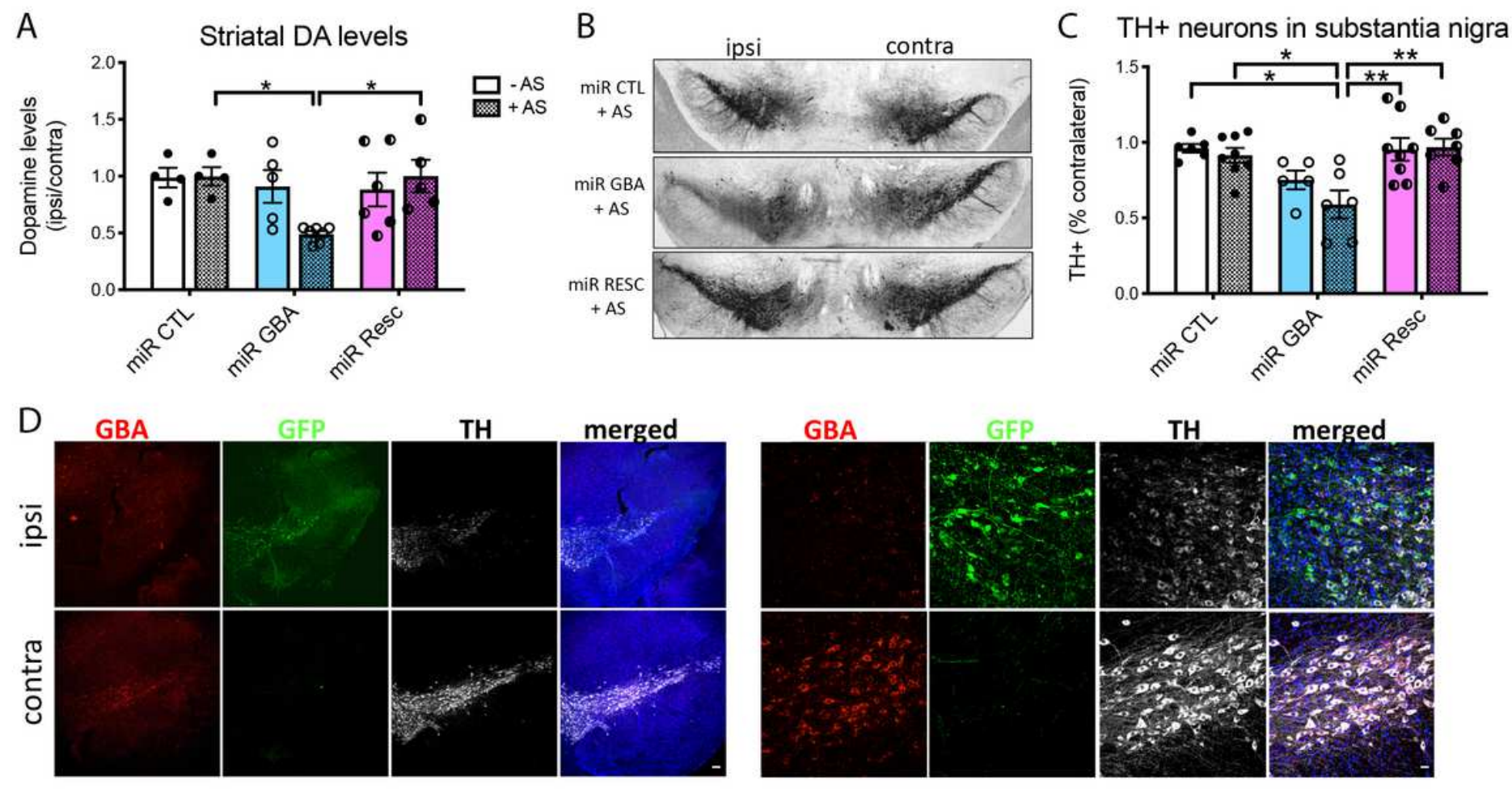

\section{Figure 3}

MicroRNA-mediated downregulation of GBA (miR GBA) in combination with human a-synuclein (AS) overexpression leads to dopaminergic nigrostriatal neurodegeneration. Unilateral injection of GFP-miR GBA + human AS (miR GBA + AS) in the striatum demonstrates: reduced striatal dopamine (DA) levels ((ipsi)lateral vs. (contra)lateral) compared with miR control + AS (miR CTL + AS) $(p=0.047)$ and miR rescue + AS (miR Resc + AS) $(p=0.027)(A)$; decreased tyrosine hydroxylase-positive $(\mathrm{TH}+)$ neurons in the substantia nigra on the (ipsi)lateral side of miR GBA + AS-injected mice as depicted in the representative 
images (10x) (B); quantification of stereological counts (\% contra), demonstrates the same decrease compared with miR CTL +/- AS ( $p=0.021,0.0061$, respectively) and miR Resc $+/$ - $A S(p=0.0033,0.0037$, respectively) (C); and representative immunofluorescent images in the substantia nigra of the ipsi(lateral) (injected; top panel) vs. contra(lateral) (non-injected; bottom panel) hemisphere of miRNA GBA-GFP (green) and AS-injected 2 month old mice depicting downregulation of GBA (red) in TH+ cell bodies (pseudocolor) and merged images with DAPI nuclear staining (blue) (D); left panels 10x (scale bar: 100 $\mu \mathrm{m})$, right panels $40 x$ (scale bar: $25 \mu \mathrm{m}) ;{ }^{*} \mathrm{p}<0.05,{ }^{*} \mathrm{p}<0.001$.

A
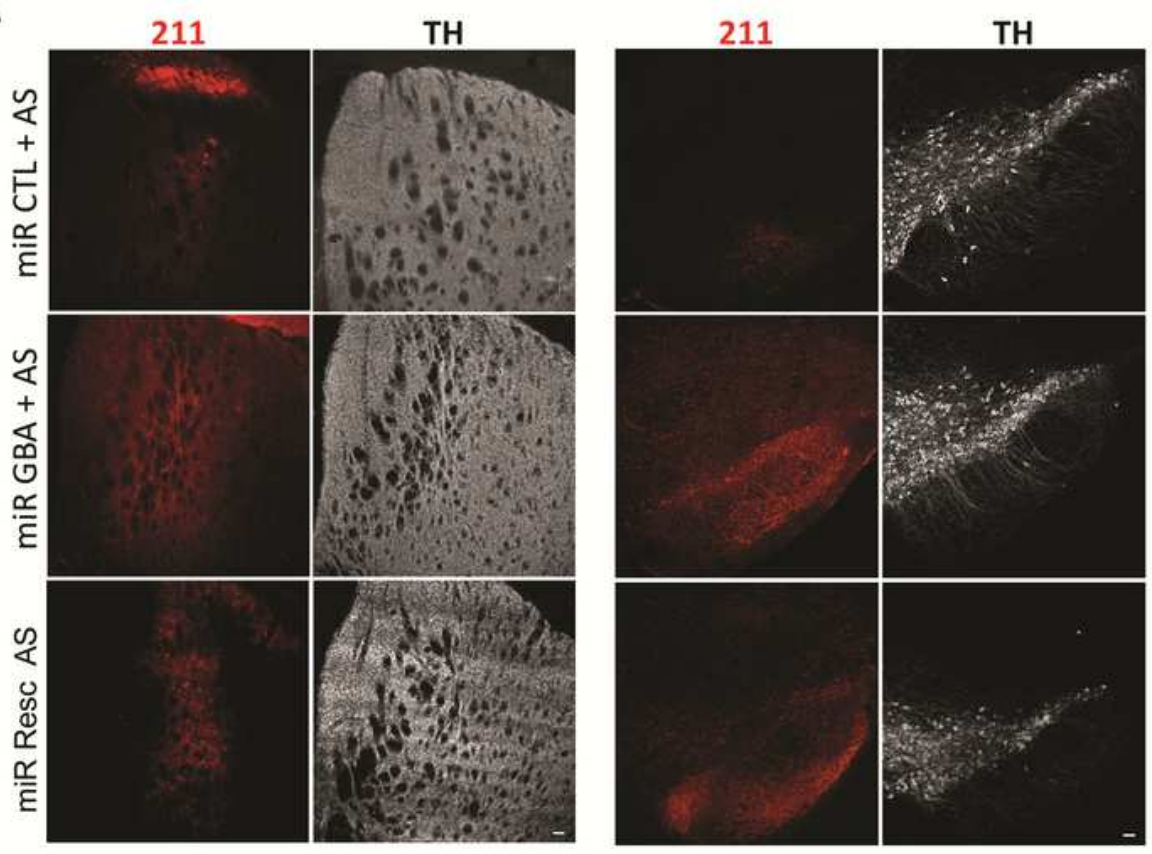

B

Human AS (211) striatum

C Human AS (211) substantia nigra
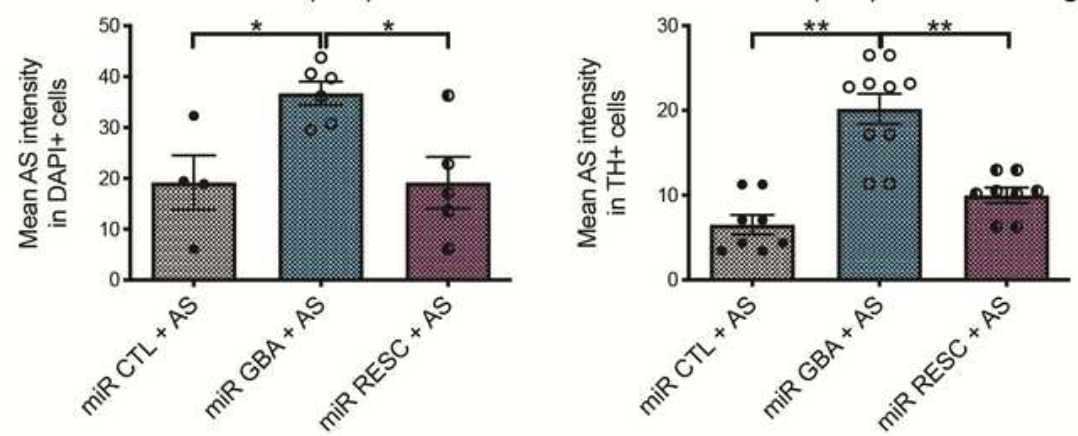

D

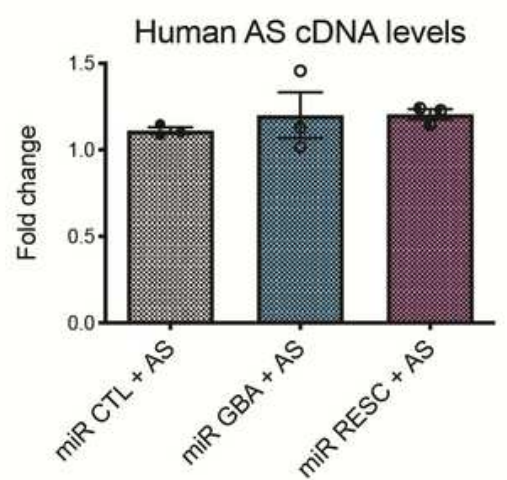

E

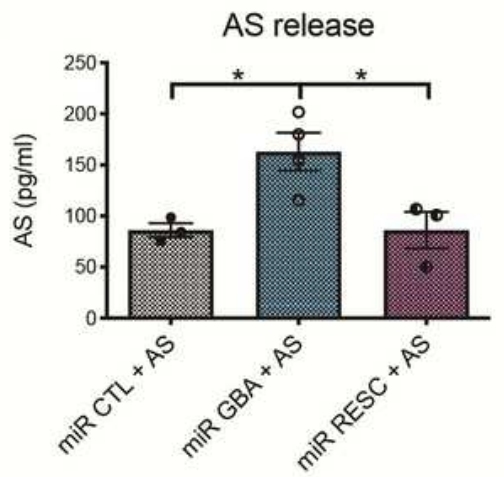




\section{Figure 4}

microRNA-mediated GBA (miR GBA) downregulation enhances human a-synuclein (AS) expression and release. Representative immunofluorescent images of human AS (211, red) staining in miR control (miR CTL)-, miR GBA- and miR rescue GBA (miR Resc)-injected in combination with human AS (+AS) in the striatum (left panel) and substantia nigra (right panel) with dopaminergic terminals and cell bodies, respectively, stained with tyrosine hydroxylase (TH, pseudo color) (A) (scale bar: $100 \mu \mathrm{m}$ ); quantification revealed a statistically significant increase in human AS expression following miR GBA + AS treatment in the striatum $(p=0.012)(B)$; and in the substantia nigra $(p<0.0001)(C)$ compared to miR $C T L+A S$ and these effects were reversed in the miR Resc + AS group; cDNA levels of human AS, measured with qPCR (fold change) in ipsilateral vs. contralateral ventral midbrain tissue of the same mice, were not altered between the different treatment groups (D); in vivo microdialysis revealed enhanced extracellular AS release in the striatum of miR GBA + AS-injected mice compared to miR CTL + AS-injected mice and these effects were reversed in the miR Resc + AS group (E). ${ }^{*} p<0.05,{ }^{* \star} p<0.001$. 
Striatum

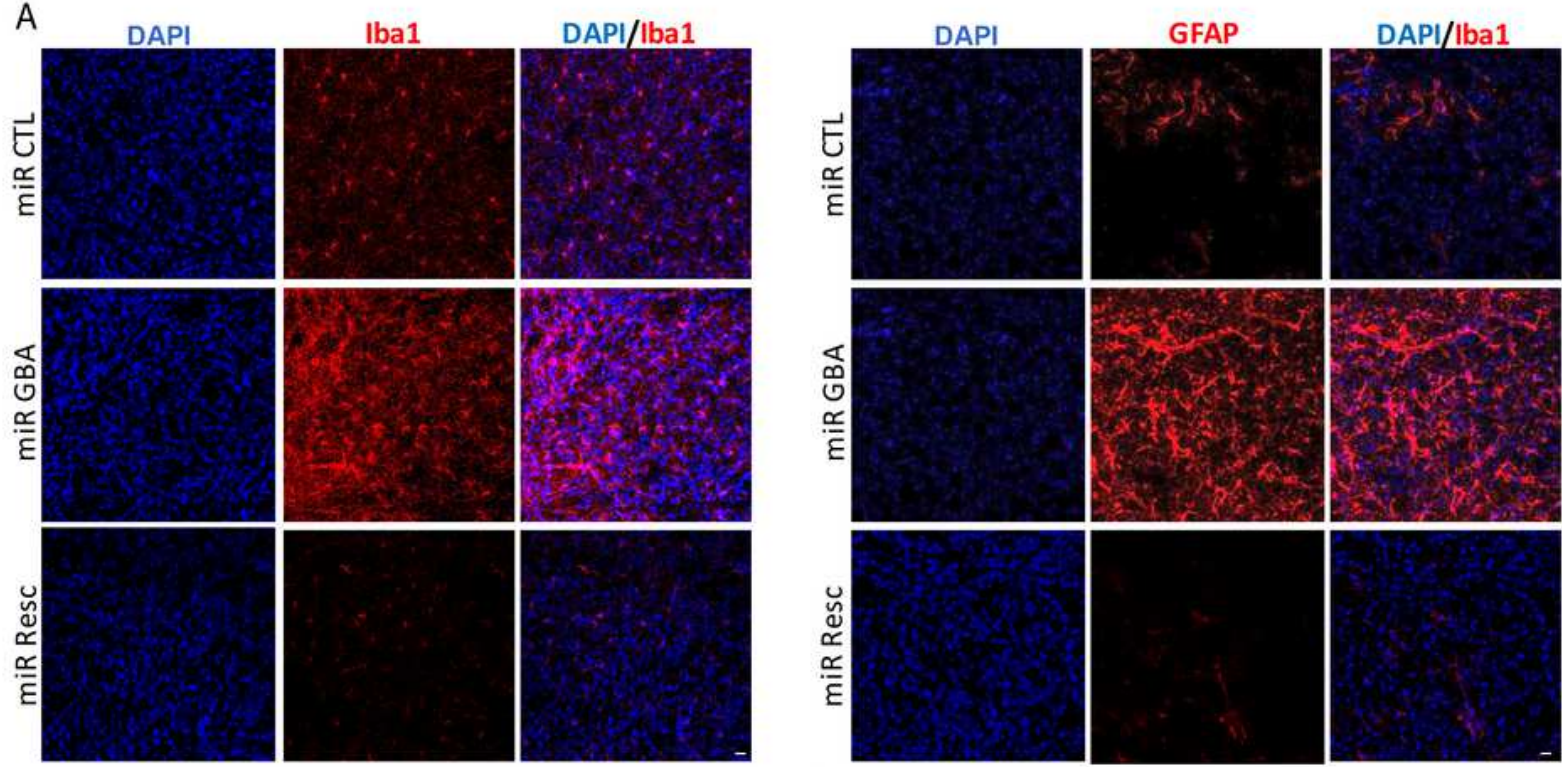

Substantia nigra
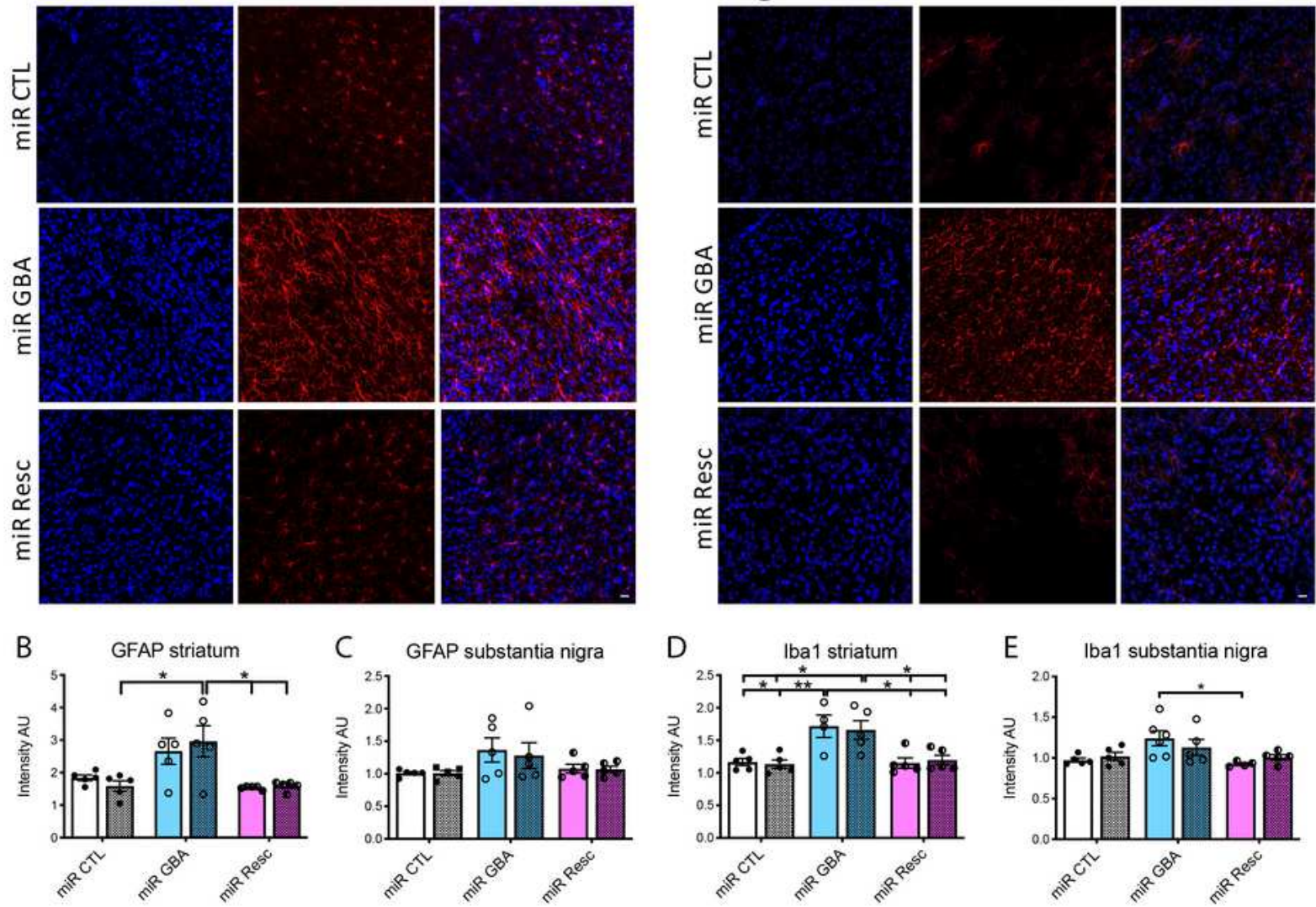

\section{Figure 5}

microRNA (miR)-mediated GBA (miR GBA) downregulation in the striatum induces astro- and microgliosis along the nigrostriatal axis. Representative immunofluorescent images of GFAP (marker for astrocytes, left panels) or AlF1/Iba1 (marker for microglia, right panels), DAPI (nuclear staining, blue) and merged images (DAPI/GFAP or DAPI/lba1, respectively) in the striatum (upper panels) and substantia nigra (lower panels) of mice injected with miR control (miR CTL), miR GBA or miR rescue (miR Resc) (A) (scale bar: 25 
$\mu m$ ). Quantification of GFAP intensity (expressed in arbitrary units (AU)) demonstrated increased expression in the mir GBA + a-synuclein (miR GBA + AS) group vs. miR CTL + AS and miR Resc +/- AS $(p=0.0001)(B)$ in the striatum and the same trend persisted in the substantia nigra $(p=0.033$, no post hoc differences) (C); quantification of Iba1 intensity (expressed in $A U$ ) revealed increased expression in miR GBA +/- AS compared to miR CTL +/- AS groups and effective reversal in miR Resc +/- AS groups $(p<0.0001)$ in the striatum (D); in the substantia nigra, lba1 expression was increased in the miR GBA AS group vs. miR Resc - AS group $(p=0.0054)(E) .{ }^{*} p<0.05,{ }^{\star \star} p<0.001$.

\section{Supplementary Files}

This is a list of supplementary files associated with this preprint. Click to download.

- SIGBAPolissidis.pdf 